\title{
INFLUÊNCIA DE TELAS DE SOMBREAMENTO DE DIFERENTES COLORAÇÕES NO DESENVOLVIMENTO DA ALFACE AMERICANA
}

\section{BIOENG}

\author{
L. L. Rech ${ }^{1}$, A. R. Lopes $^{2 *}$, M. Dotto ${ }^{1}$, C. M. Giarola ${ }^{3}$, K. Pirola ${ }^{4}$
}

${ }^{1}$ UNISEP - Centro Universitário, Dois Vizinhos, PR, Brasil

${ }^{2}$ UNIOESTE - Universidade Estadual do Oeste do Paraná, Cascavel, PR, Brasil

${ }^{3}$ UNIPAR - Universidade Paranaense, Umuarama, PR, Brasil

${ }^{4}$ UTFPR - Universidade Tecnológica Federal do Paraná, Pato Branco, PR, Brasil

Article history: Received 03 November 2019; Received in revised form 11 November 2019; Accepted 14 November 2019; Available online 05 December 2019.

\section{RESUMO}

A utilização das telas coloridas visa uma melhor proteção contra a radiação solar. Este trabalho teve como objetivo avaliar a influência de diferentes cores nas telas de sombreamento no desenvolvimento da alface americana. $\mathrm{O}$ experimento foi conduzido no município de São João, Paraná. O delineamento experimental foi em blocos casualizados (DBC) com 6 tratamentos e 4 repetições, sendo eles: T1: Testemunha (cultivo a céu aberto), T2: Tela de sombreamento azul, T3: Tela de sombreamento prata, T4: Tela de sombreamento preta, T5: Tela de sombreamento verde e T6: Tela de sombreamento vermelha. O desenvolvimento da alface foi avaliado quanto ao peso da raiz, comprimento da raiz, diâmetro da cabeça, número de folhas, massa fresca e peso da cabeça. A alface sem tela de sombreamento apresentou o melhor desenvolvimento, dentre as telas de sombreamento estudadas a tela vermelha obteve um destaque negativo, sempre com o pior desempenho agronômico.

Palavras-chave: Lactuca sativa L. Ambiente protegido, Desempenho da cultura.

\section{INFLUENCE OF DIFFERENT COLOR SHADING SCREENS ON AMERICAN LETTUCE DEVELOPMENT}

\begin{abstract}
The use of color shading screens aims at better protect against solar radiation. This study aimed to evaluate the influence of different colors on shading screens on the development of american lettuce. The experiment was conducted in São João, Paraná. The experimental design was randomized complete block design (DBC) with 6 groups and 4 replications: T1: Open field cultivation, T2: Blue shading Screen, T3: Silver shading screen, T4: Black shading screen, T5: Green shading screen and T6: Red shading screen. Lettuce development was evaluated for root weight, root length, head diameter, leaf number, fresh mass and head weight. Lettuce without shading screen presented the best development, among the studied shading screens the red schading screen had a negative highlight, Always with the worst agronomic performance.
\end{abstract}

Keywords: Lactuca sativa L, Greenhouse, Crop performance.

\footnotetext{
"allanremorlopes@gmail.com
} 


\section{INTRODUÇÃO}

A alface (Lactuca sativa L.) tem sido cultivada desde a antiguidade, sendo a hortaliça folhosa mais produzida e consumida no mundo (MONTEIRO NETO et al., 2014). No Brasil, o plantio da alface ocupa uma área de aproximadamente 35000 hectares, sendo que a alface do tipo crespa possui maior importância econômica com $70 \%$ de preferência no mercado brasileiro, seguido pela alface americana com 15\% (SUINAGA et al., 2013).

Apesar da elevada importância econômica, em grande parte os métodos de produção são rudimentares, não correspondendo às expectativas de produções esperadas (QUEIROGA et al., 2001).

Nas últimas décadas, o cultivo em ambiente protegido no Brasil apresentou crescimento significativo, principalmente para produção de hortaliças. Considerando a importância alimentar das hortaliças, seu elevado valor econômico, principalmente na entressafra, tornam-se necessárias

\section{MATERIAL E MÉTODOS}

O experimento foi realizado de 06 de junho a 20 de julho, em ambiente protegido em uma propriedade rural no município de São João, estado do Paraná ( $25^{\circ} 49^{\prime} 40^{\prime \prime} \mathrm{S}$ e $\left.52^{\circ} 43^{\prime} 31^{\prime \prime} \mathrm{W}\right)$. O clima, conforme a classificação de Köppen, é do tipo Cfa, subtropical úmido.

Para a produção das mudas, foi utilizado um substrato com mistura de húmus e vermiculita, na proporção de $2: 1$, isento de pragas e doenças, sendo portanto, indicado para produção de mudas de hortaliças. Aos sete dias de emergência, foi realizado o desbaste, deixando-se uma planta por célula.

A cultivar utilizada de alface americana utilizada no experimento foi a Lucy Brown. Logo após o transplantio das mudas, aos 22 dias, foram colocadas as telas de nylon, a $50 \mathrm{~cm}$ de altura dos canteiros. Os canteiros mediam $10 \mathrm{~m}$ de comprimento, $1,20 \mathrm{~m}$ de largura, e $0,20 \mathrm{~m}$ pesquisas com $\mathrm{o}$ intuito de oferecer tecnologias de aumento de produtividade e redução de riscos (MAGGI et al., 2006).

As modificações climáticas que ocorrem em cada tipo de ambiente protegido dependem do tipo de cobertura empregada. Estufa, túnel, agrotextil e malha de sombreamento, tem sido muito utilizadas para proteção de cultivo. Dentre estas, as telas de sombreamento são as mais conhecidas, que pode apresentar variações na absorção e bloqueio de luminosidade (RAMPAZZO et al., 2013).

As telas coloridas apresentam um novo conceito agrotecnológico, tendo como finalidade combinar a proteção física com a filtração diferencial da radiação solar, para promover respostas fisiológicas especificas que são reguladas pela luz (Brant et al. 2009).

Sendo assim, o objetivo deste trabalho foi avaliar a influência das diferentes cores de sombreamento no desenvolvimento da alface americana "Lucy Brown".

de altura, distanciados $0,5 \mathrm{~m}$ dos demais canteiros. Na adubação de plantio foi utilizado $80 \mathrm{t} \mathrm{ha}^{-1}$ de esterco bovino.

$\mathrm{O}$ delineamento experimental usado foi de blocos casualizados (DBC), com 4 repetições e 6 tratamentos, utilizando diferentes tipos de telas de sombreamento. Sendo eles: T1: Testemunha (cultivo a céu aberto), T2: Tela de sombreamento azul, T3: Tela de sombreamento Prata, T4: Tela de sombreamento Preta, T5: Tela de sombreamento Verde e T6: Tela de sombreamento Vermelha.

As irrigações foram realizadas em 2 turnos: Início da manhã e final da tarde, de forma a manter o teor de umidade do solo sempre próximo a capacidade de campo. Foram realizadas três capinas manuais, visando à manutenção da cultura sempre no limpo.

As plantas foram colhidas quando começaram a tender ao pendoamento, e 
levadas ao laboratório, onde foram avaliadas as seguintes características: Peso da raiz $(\mathrm{g})$, comprimento da raiz $(\mathrm{cm})$, diâmetro da cabeça $(\mathrm{cm})$, número de folhas, massa fresca $(\mathrm{g})$ e peso da cabeça (g).

\section{RESULTADOS E DISCUSSÃO}

As telas azul e verde junto com a alface sem tela de sombreamento (Testemunha) apresentaram maior peso da raiz (Tabela 1), com 13,10 e 12,14 g,
Os dados médios foram submetidos à análise de variância pelo teste $\mathrm{F}$, e as médias comparadas pelo teste de Tukey a $5 \%$ de probabilidade. O software utilizado foi o WINSTAT.

Tabela 1. Peso da raiz (g) da alface em função das diferentes telas de sombreamento.

\begin{tabular}{cc}
\hline Tratamentos & Peso da raiz $(\mathrm{g})$ \\
\hline T1: Testemunha & $12,66^{\mathrm{a}}$ \\
T2: Tela Azul & $13,10^{\mathrm{a}}$ \\
T3: Tela Prata & $8,88^{\mathrm{b}}$ \\
T4: Tela Preta & $11,67^{\mathrm{b}}$ \\
T5: Tela Verde & $12,14^{\mathrm{a}}$ \\
T6: Tela Vermelha & $8,85^{\mathrm{b}}$ \\
\hline
\end{tabular}

*Médias com as mesmas letras na coluna não apresentam diferenças significativas pelo Teste de Tukey a $5 \%$.

A Tabela 2 demonstra os valores do comprimento da raiz com as diferentes telas de sombreamento. A Tela Prata, Preta, Verde e Testemunha apresentaram os maiores tamanhos de raiz, com 12,20 $\mathrm{cm}, 14,10 \mathrm{~cm}, 12,70 \mathrm{~cm}$ e $11,97 \mathrm{~cm}$ respectivamente. Todos os valores obtidos se mostraram superiores ao estudo de Pinto et al. (2018), que verificaram a produção de alface em hortas urbanas com diferentes durações de luminosidade e recipientes, obtendo valores de 5,9 a $7,9 \mathrm{~cm}$.

Tabela 2. Comprimento da raiz $(\mathrm{cm})$ da alface em função das diferentes telas de sombreamento.

\begin{tabular}{cc}
\hline Tratamentos & Comprimento da raiz $(\mathrm{cm})$ \\
\hline T1: Testemunha & $11,97^{\mathrm{ab}}$ \\
T2: Tela Azul & $11,77^{\mathrm{b}}$ \\
T3: Tela Prata & $12,20^{\mathrm{ab}}$ \\
T4: Tela Preta & $14,10^{\mathrm{a}}$ \\
T5: Tela Verde & $12,70^{\mathrm{ab}}$ \\
T6: Tela Vermelha & $11,72^{\mathrm{b}}$ \\
\hline
\end{tabular}

*Médias com as mesmas letras na coluna não apresentam diferenças significativas pelo Teste de Tukey a $5 \%$.

O diâmetro da cabeça pode ser verificado na Tabela 3 . Os maiores diâmetros foram atribuídos a alface sem tela de sombreamento e com a tela prata, com $15,18 \mathrm{~cm}$ e $14,70 \mathrm{~cm}$. Assim como no trabalho de Bezerra Neto et al. (2005) o uso da tela não promoveu acréscimo no diâmetro da cabeça da alface. O fato da alface a céu aberto possuir maior diâmetro pode ser explicado pela morfologia particular que as folhas produzidas a céu aberto desenvolveram. 
Tabela 3. Diâmetro da cabeça $(\mathrm{cm})$ da alface em função das diferentes telas de sombreamento.

\begin{tabular}{cc}
\hline Tratamentos & Diâmetro da cabeça $(\mathrm{cm})$ \\
\hline T1: Testemunha & $15,18^{\mathrm{a}}$ \\
T2: Tela Azul & $12,25^{\mathrm{d}}$ \\
T3: Tela Prata & $14,70^{\mathrm{ab}}$ \\
T4: Tela Preta & $13,84^{\mathrm{bc}}$ \\
T5: Tela Verde & $13,15^{\mathrm{cd}}$ \\
T6: Tela Vermelha & $13,84^{\mathrm{bc}}$
\end{tabular}

*Médias com as mesmas letras na coluna não apresentam diferenças significativas pelo Teste de Tukey a $5 \%$.

O número de folhas está apresentado na Tabela 4. A alface sem tela de sombreamento (Testemunha) e com Tela Verde, apresentaram o maior número de folhas, com 30,20 e $29,95 \mathrm{~cm}$, respectivamente. Queiroga et al. (2001), obtiveram estudando diferentes telas em função de cultivares na produção de alface obtiveram uma média de 19,22 folhas por planta utilizando tela verde.

Tabela 4. Número de folhas da alface em função das diferentes telas de sombreamento.

\begin{tabular}{cc}
\hline Tratamentos & Número de folhas \\
\hline T1: Testemunha & $30,20^{\mathrm{a}}$ \\
T2: Tela Azul & $28,00^{\mathrm{b}}$ \\
T3: Tela Prata & $26,62^{\mathrm{c}}$ \\
T4: Tela Preta & $26,12^{\mathrm{c}}$ \\
T5: Tela Verde & $29,95^{\mathrm{a}}$ \\
T6: Tela Vermelha & $27,16^{\mathrm{bc}}$ \\
\hline
\end{tabular}

*Médias com as mesmas letras na coluna não apresentam diferenças significativas pelo Teste de Tukey a $5 \%$.

$\mathrm{Na}$ Tabela 5 encontra-se a massa fresca da alface com diferentes telas de sombreamento. A alface sem tela de sombreamento (Testemunha) obteve a maior massa fresca com 660,12 g e a menor com a Tela Azul (431,24 g). Para Ribeiro et al. (2006), a utilização de telas de sombreamento não melhorou a massa da alface em cultivo hidropônico. Os resultados corroboram com Costa et al. (2011), que também obtiveram a menor massa fresca de frutos de morangueiros com a tela azul.

Dalastra et al. (2016) ao estudarem o desempenho produtivo de alface, cultivado sob telado, em níveis diferentes de sombreamento, observaram maiores médias de massa de planta sem sombreamento. Para Hirata \& Hirata (2016), as telas de sombreamento atuam com um impacto negativo no inverno, devido ao excesso de sombreamento.

Tabela 5. Massa fresca (g) da alface em função das diferentes telas de sombreamento.

\begin{tabular}{cc}
\hline Tratamentos & Massa fresca $(\mathrm{g})$ \\
\hline T1: Testemunha & $660,12^{\mathrm{a}}$ \\
T2: Tela Azul & $431,24^{\mathrm{c}}$ \\
T3: Tela Prata & $516,37^{\mathrm{b}}$ \\
T4: Tela Preta & $476,77^{\mathrm{bc}}$ \\
T5: Tela Verde & $499,23^{\mathrm{bc}}$ \\
T6: Tela Vermelha & $491,33^{\mathrm{bc}}$ \\
\hline
\end{tabular}

*Médias com as mesmas letras na coluna não apresentam diferenças significativas pelo Teste de Tukey a $5 \%$. 
Na Tabela 6, é apresentado o peso da alface com as diferentes telas de sombreamento. A alface sem tela, com tela prata, verde e vermelha apresentaram os maiores pesos da cabeça, com 324,87, $279,47, \quad 300,11$ e $286,50 \mathrm{~cm}$, respectivamente. Ou seja, o uso da tela de sombreamento não proporcionou um aumento no peso da cabeça.

Diamante et al. (2013) ao avaliarem diferentes cultivares de alface em diferentes ambientes, durante abril e maio, também concluíram que os ambientes protegidos não apresentaram um aumento do peso da cabeça.

Tabela 6. Peso da cabeça (g) da alface em função das diferentes telas de sombreamento.

\begin{tabular}{cc}
\hline Tratamentos & Peso da cabeça $(\mathrm{g})$ \\
\hline T1: Testemunha & $324,87^{\mathrm{a}}$ \\
T2: Tela Azul & $231,37^{\mathrm{b}}$ \\
T3: Tela Prata & $279,47^{\mathrm{ab}}$ \\
T4: Tela Preta & $250,19^{\mathrm{b}}$ \\
T5: Tela Verde & $300,11^{\mathrm{ab}}$ \\
T6: Tela Vermelha & $286,50^{\mathrm{ab}}$ \\
\hline
\end{tabular}

*Médias com as mesmas letras na coluna não apresentam diferenças significativas pelo Teste de Tukey a $5 \%$.

Dentre as diferentes cores estudadas, a tela vermelha apresentou o pior desempenho. Henrique et al. (2011) ao estudarem aspectos fisiológicos na produção de mudas de café, concluíram que a tela vermelha foi a mais eficiente na produção de mudas, com maior vigor e qualidade.

Os dados da pesquisa corroboram com Ricardo et al. (2014), que ao compararem diferentes telas no desenvolvimento da alface, concluíram que

\section{CONCLUSÕES}

Para todos os parâmetros analisados, a tela vermelha proporcionou um pior desenvolvimento da alface americana cv. Lucy Brown.

\section{REFERÊNCIAS BIBLIOGRÁFICAS}

BEZERRA NETO, F.; ROCHA, R. C. C.; NEGREIROS, M. Z.; ROCHA, R. H.; QUEIROGA, R. C. F. Produtividade de alface em função de condições de sombreamento e temperatura e luminosidade elevadas. Horticultura Brasileira, v. 23, n. 2, p. 189-192, 2005.

BRANT, R. Da S.; PINTO, J. E. B. P.; ROSA, L. F.; ALBUQUERQUE, C. J. B.; a produção foi menor nos ambientes com as telas, sendo que para o cultivo de inverno recomenda-se o cultivo a campo aberto. O desempenho da alface é dependente das condições climáticas do local de cultivo, pois em condições de verão ocorre uma maior produção de alface com telas de sombreamento. Porém, em condições favoráveis ao desenvolvimento da planta (inverno) a planta se desenvolve melhor a céu aberto (Seabra Júnior et al., 2010).

O melhor desenvolvimento foi observado para a alface americana cv. Lucy Brown sem tela de sombreamento.

FERRI, P. H.; CORRÊA, R. M. Crescimento, teor e composição do óleo essencial de melissa cultivada sob malhas fotoconversas. Ciência Rural, v. 39, p. 1401-1407, 2009.

COSTA, R. C.; CALVETE, E. O.; REGINATTO, F. H.; CECCHETTI, D.; LOSS, J. T.; RAMBO, A.; TESSARO, F. Telas de sombreamento na produção de 
morangueiro em ambiente protegido. Horticultura Brasileira, v. 29, n. 1, p. 98102, 2011.

DALASTRA, M. G.; HACHMANN, T. L.; ECHER, M. M.; GUIMARÃES, F. V.; FIAMETTI, M. S.; Características produtivas de cultivares de alface mimosa conduzida sob diferentes níveis de sombreamento, no inverno. Scientia Agraria Paranaensis, v. 15, p. 15-19, 2016.

DIAMANTE, M. S.; SEABRA JÚNIOR, S.; INAGAKI, A. M.; SILVA, M. B.; DALLACORT, R. Produção e resistência ao pendoamento de alfaces tipo lisa cultivadas sob diferentes ambientes. Revista Ciência Agronômica, v. 44, n. 1, p. 133-140, 2013.

HENRIQUE, P. C.; ALVES, J. D.; DEUNER, S.; GOULART, P. F. P.; LIVRAMENTO, D. E. Aspectos fisiológicos do desenvolvimento de mudas de café cultivadas sob telas de diferentes colorações. Pesquisa Agropecuária Brasileira, v. 46, n. 5, p. 458-465, 2011.

HIRATA, A. C. S.; HIRATA, E. K. Telas de sombreamento no cultivo de hortaliças folhosas. Pesquisa e Tecnologia, v. 13, n. 1, 2016.

MAGGI, M. F.; KLAR, A. E.; JADOSKI, C. J.; ANDRADE, A. R. S. Produção de variedades de alface sob diferentes potenciais de água no solo em ambiente protegido. Irriga, v. 11, n. 3, p. 415-427, 2006.

MONTEIRO NETO, J. L. L.; SILVA, A. C. D.; SAKAZAKI, R. T.; TRASSATO, L. B.; ARAÚJO, W. F. Tipos de cobertura no solo no cultivo de alface (Lactuca sativa L.) sob as condições climáticas de Boa Vista, Roraima. Boletim do Museu Integrado de Roraima, v. 8, n. 2, p. 47$52,2014$.

PINTO, A. A.; SANTANA, L. D.; CAMAR, F. T.; RODRIGUES, W. A. D.; SILVA, F. E. Duração da luminosidade e tamanho de recipientes para a produção de alface em hortas urbanas. Revista de
Agricultura Neotropical, v. 5, n. 3, p. 2029, 2018.

QUEIROGA, R. C. F.; BEZERRA NETO, F.; NEGREIROS, M. Z.; OLIVEIRA, A. P.; AZEVEDO, C. M. S. B. Produção de alface em função de cultivares e tipos de tela de sombreamento nas condições de Mossoró. Horticultura Brasileira, v. 19, n. 3, p. 324-328, 2001.

RAMPAZZO, R.; SEABRA JÚNIOR, S.; NUNES, M. C. M.; NEVES, S. M. A. S.; FERREIRA, R. F. Eficiência de telas termorefletoras e de sombreamento em ambiente protegido tipo telado sob temperaturas elevadas. Engenharia na Agricultura, v. 22, n. 1, p. 33-42, 2014.

RIBEIRO, M. C. C.; BENEDITO, C. P.; LIMA, M. S.; FREITAS, R. S.; MOURA, M. C. F. Influência do sombrite no desenvolvimento da alface em cultivo hidropônico. Revista Verde de Agroecologia e Desenvolvimento Sustentável, v. 2, n. 2, p. 69-72, 2007.

RICARDO, A. S.; VARGAS, P. F.; FERRARI, S.; PAVARINI, G. M. P. Telas de sombreamento no desempenho de cultivares de alface. Nucleus, v. 11, n. 2, p. 433-441, 2014.

SOUZA, G. S.; SILVA, J. S.; OLIVEIRA, U. C.; SANTOS NETO, R. B.; SANTOS, A. R. Crescimento vegetativo e produção de óleo essencial de plantas de alecrim cultivadas sob telas coloridas. Bioscience Journal, v. 30, suplementar 1, p. 232-239, 2014.

SUINAGA, F. A.; BOITEUX, L. S.; CABRAL, C. S.; RODRIGUES, C. da S. Métodos de avaliação do florescimento precoce e identificação de fontes de tolerância ao calor em cultivares de alface do grupo varietal crespa. Brasília, DF: Embrapa Hortaliças, 2013, 4 p. (Embrapa Hortaliças. Comunicado Técnico, 89). 